\section{CYTOLOGICA}

Albuquerque, A. 118

Amorrortu, R.P. 100

Cuschieri, K. 85

de Oliveira, C.M. 97, 159

Fregnani, J.H.T.G. 159

Giuliano, A.R. 109

Jaakola, A. 148

Alcohol 124

Alpha-papillomavirus 97

Anal cancer 118

- intraepithelial neoplasia 118

- squamous intraepithelial lesions 118

- warts 118

Cell biology 100

Cell-mediated immunity 148

Cervical cancer 85, 148

Clinical efficacy 159

- trials 159

Cohort study 109

Concordance 143

Epidemiology 124

Evolution 97
Kero, K. 143

Longatto-Filho, A. 1, 83

Lorincz, A.T. 85

Louvanto, K. 148

Medeiros, R. 118

Nedjai, B. 85

Paaso, A. 148
Rautava, J. 143

Rollison, D.E. 100

Sichero, L. 100, 109

Syrjänen, K. 124

Syrjänen, S. 124, 148

Tommasino, M. 100

Villa, L.L. 109, 159

\title{
Subject Index Vol. 63, No. 2, 2019
}

Head and neck cancer 124

High-risk genotypes 148

HPV 109, 124

- Research Priorities Survey 85

- vaccines 159

Human leukocyte antigen system 148

- papillomavirus $85,97,100,118,143$, 148

- - vaccination 118

Infectious disease pathobiology 100

Laryngeal cancer 124

Men 109

Molecular marker 100
Oral cancer 124

Oropharyngeal cancer 124

Papillomavirus infections 159

PCR 109

Public health 100

Risk factors 124

Sexual couples 143

Sinonasal cancer 124

Smoking 124

State of the art reviews 159

Tonsillar cancer 124

Transmission 143

Virology 100 